Nakahara, W., Inukai, F. \& Kato, S. (1934). Sci. Pap. Inst. phys. chem. Res., Tokyo, 24, I55.

Nakahara, W., Inukai, F., Kato, S. \& Ugami, S. (1936). Sci. Pap. Inst. phys. chem. Res., Tokyo, $29,47$.

Nakahara, W., Inukai, F. \& Ugami, S. (1939). Sci. Pap. Inst. phys. chem. Res., Tokyo, 36, 327.

Nelson, M. M. \& Evans, H. M. (1945). Proc. Soc. exp. Biol., N.Y., 60, 319.

Richardson, L. R., Hogan, A. G., Long, B. \& Itschner, K. I. (1941). Proc. Soc. exp. Biol., N. Y., 46, 530.

Richardson, L. R., Long, B. \& Hogan, A. G. (1942). Amer. Chem. Soc. 1ozrd Mtg, p. B4.

Rogers, L. K., McElroy, L. W. \& Cowgill, G. R. (1942). Science, 95, 203.

Rombouts, J. E. \& Querido, A. (1946). Nature, Lond., 158, 792.

Sure, B. (r94r). F. Nutrit. 22, $49 \mathrm{r}$.

Troescher-Elam, E. \& Evans, H. M. (1941). Proc. Soc. exp. Biol., N.Y., 48, 549.

Vinson, L. J. \& Cerecedo, L. R. (1943). Fed. Proc. 2, 73.

Vinson, L. J. \& Cerecedo, L. R. (1944). Arch. Biochem. 3, 389.

Voris, L., Black, A., Swift, R. W. \& French, C. E. (1942). F. Nutrit. 23, 555.

Zucker, T. F. \& Zucker, L. (1944). Proc. Soc. exp. Biol., N.Y., 55, 136.

\title{
Formation of Fluorescent Pigment in Vitamin E Deficiency
}

\author{
By T. MOORE AND Y. L. WANG \\ Dunn Nutritional Laboratory, University of Cambridge and Medical Research Council
}

(Received 28 February 1947)

The brown discoloration of the uterus which occurs in rats deprived of vitamin $\mathrm{E}$ was first described by Martin \& Moore (1936). Later (1938) they reported that prolonged deficiency caused some degree of discoloration also in the skeletal muscles throughout the body, and particularly in the hind legs, which frequently became paralysed. The brown colour, therefore, appeared to be associated with the muscular dystrophy described by Ringsted (1935) and others, although there was some evidence that the process was not confined to muscular tissues. Thus, it was noticed that certain lymph nodes became decidedly brown. Histological examinations of the brown uterus revealed that the degenerated muscle cells were filled with small yellow granules (Barrie, 1938; Martin \& Moore, 1939). The phenomenon was studied further by Hessler (194I), Barrie Sweeten (1943), Demole (1941), Evans \& Emerson (1943), Oliveira (1946) and Faria (1946). In addition, Mason \& Emmel (1945) have recently made a detailed histological study which deserves special mention. In their opinion brown pigment is formed mainly, though not exclusively, in muscle cells, but is subsequently transferred to the tissue macrophages, and disseminated through the lymphatic system.

The purpose of the present paper is to report further experiments on the occurrence and on the chemical and physical characterization of the brown pigment, with particular reference to the fluorescent properties which have already been described in a preliminary communication (Moore \& Wang, 1943). Its characteristics will be compared with those of certain other brown pigments which have been reported by various workers to occur in the tissues of both experimental animals and human subjects. 
EXPERIMENTAL

\section{Fluorescence in animal tissues}

Rats deprived of vitamin $E$

Young female rats were killed after restriction for different periods to a diet deficient in vitamin $\mathrm{E}$, of which the percentage composition was casein 25, sugar 50, lard ro, salt mixture 5 and dried yeast 10, with one drop of halibut-liver oil per rat per week. At autopsy the fresh tissues were viewed under irradiation from a mercury arc lamp, screened with Wood's glass.

Early changes. In young females which had received the diet for about to weeks abnormal fluorescence was seen only in the uterus, which appeared a pale yellowbrown in place of the normal dull violet. This change could be clearly discerned at a stage when no abnormality in colour could be detected by inspection in ordinary light. The oviducts, ovaries, and ovarian ligaments also showed yellow fluorescence at an early stage of deficiency.

Changes in advanced deficiency. After more prolonged deficiency the occurrence of fluorescence was extensive. Thus, in an animal deprived of vitamin $\mathrm{E}$ for 19 months, the uterus appeared a rich yellow-bronze. Less intense fluorescence was seen throughout the skeletal musculature, and in those sites, such as the retro-peritoneal lymph glands and subcutaneous areolar tissues, in which brown pigmentation had previously been observed. The general effect was to make the flesh of the deficient animal throughout the body appear yellowish brown, in distinct contrast with the dull violet colour of the normal animal. Yellow fluorescence was observed also in the diaphragm, except for a small area surrounding the point of entry of the oesophagus. The heart and kidneys also had a brown tint, although the fluorescence was less obvious, and could only be discerned by comparison beside normal organs. Tissues in which the fluorescence remained normal included the urinary bladder, the appearance of which was in contrast with that of the adjacent tissues of the uterus. The lungs showed no yellow fluorescence, and any abnormal fluorescence in the intestines could usually be ascribed to staining with bile.

Examination under low magnification of the ovaries of rats kept on the deficient diet for I 3 months indicated that fluorescence was most intense in the stroma. The Graafian follicles when teased apart appeared less brown than the stroma in visible light, and displayed only faint fluorescence. Liquid expressed from the follicles was not fluorescent.

Embryos growing in the brown pigmented uterus of a deficient rat showed no abnormality in either colour or fluorescence. The animal examined was 9 months old and, after receiving a diet deficient in vitamin $\mathrm{E}$ since weaning, had been placed with a male for 20 days. Six embryos of a maximum length of $0.75 \mathrm{~cm}$. were found, and their dull violet fluorescence was in sharp contrast with the yellow of the interior of the uterus.

Stability in the tissues of the fluorescent substance. The yellow fluorescence in all the sites mentioned was observed in fresh tissues within a few minutes after the animal had been killed. In animals which had died the yellow fluorescence of the uterus was 
still obvious in portions of the tissues which had become black with putrefaction, although no yellow fluorescence was shown by a normal uterus at the same stage of decomposition.

\section{Guinea-pigs deprived of vitamin $E$}

In view of the regularity of the appearance of brown pigmentation and fluorescence in the tissues of rats deficient in vitamin $\mathrm{E}$, it was considered of interest to repeat the experiments with another species. For this purpose the guinea-pig was chosen, since it is known to be susceptible to muscular dystrophy when deprived of vitamin $\mathrm{E}$. The basal diet differed from that used for rats in containing roughage. Its percentage composition was casein 15 , starch 35 , sugar 10 , agar agar 20 , dried yeast 10 , lard 6 and salt mixture 4. Vitamins A and D were supplied as 4 drops of 'Radiostoleum' (The British Drug Houses Ltd.) weekly per animal. Each animal was given $5 \mathrm{mg}$. ascorbic acid daily.

Since some difficulty was experienced in establishing small guinea-pigs on the basal diet, nearly fully grown females of body weight 480 to $600 \mathrm{~g}$. were used. Out of six animals two died after receiving the basal diet for 2 months. The uterus and skeletal muscles were normal in colour, and there was no yellow fluorescence on irradiation. Another animal was killed when moribund after receiving the diet for 7 months, and again there was no abnormal pigmentation or fluorescence. The remaining three animals died or were killed after II-13 months. All, when tested a few weeks before death, showed some degree of paralysis, and were unable to right themselves when placed on their backs. In only one instance was any abnormal brown pigmentation or fluorescence observed, and it was confined to the inner lining of the uterus.

Successful experiments with younger animals, and with histological examination for pigment cells, are obviously necessary before it can be concluded that the guineapig differs fundamentally from the rat in regard to pigment formation. Evidence to the contrary may be found in reports that brown pigment occurs in the atrophic tubules of the testes of guinea-pigs kept on a diet deficient in vitamin $E$ for about 6 months (Pappenheimer \& Schogoleff, r944; Pappenheimer \& Victor, 1946). It seems safe to assume, however, that pigment is formed much less readily than in the rat.

\section{Human tissues}

Martin \& Moore (1939) have already pointed out that the deposit of brown pigment in rats deprived of vitamin $E$ closely resembles that which occurs in certain pathological conditions, and in old age, in the human subject. It was, therefore, decided to include human material in the present investigation. The heart of an old man, which on superficial inspection at autopsy appeared to be affected by brown atrophy, was examined first. Under ultra-violet irradiation a deep yellowish brown fluorescence was seen, which was not unlike that shown by the uterus of the rat at a stage when prolonged deficiency of vitamin $\mathrm{E}$ has caused the initial yellow-brown to change to a deep bronze shade. 
In other human hearts, however, fluorescence was often observed, but bore no relation in intensity and shade to the age or cause of death of the subject. In some hearts patches of bright red fluorescence, suggestive of the presence of porphyrins, were seen on a background of dull brown. Other hearts had a 'normal' dark violet appearance.

An explanation of these divergencies was found in the effects of storage of the heart on its fluorescent properties. If in a heart showing red or brown fluorescence a fresh area of muscle was exposed by section, the new surface did not display abnormal fluorescence. The conclusion that storage affected fluorescence was confirmed by observations on a pig's heart, which had a violet fluorescence when fresh, but appeared reddish brown after keeping for some days in a refrigerator. Observations on the fluorescence of human hearts must, therefore, have doubtful significance, unless precautions against deterioration are taken to an extent which was impracticable in the present work.

Specimens of human skeletal muscle and uteri showed little abnormal fluorescence even when stored for long periods. A specimen of peritoneal muscle and the appendix taken at operation from a boy suffering from muscular dystrophy showed a normal dull violet fluorescence. No evidence of the bright yellow-brown fluorescence typical of early vitamin $E$ deficiency in the rat was found in any of the human tissues under examination.

\section{Separation of a brown fluorescent pigment}

The pigment in the tissues of rats deprived of vitamin $\mathrm{E}$ was insoluble in organic solvents, including ether, ethanol, acetone and pyridine. It was insoluble also in dilute $\mathrm{HCl}$, but was slightly soluble in cold $10 \% \mathrm{NaOH}$. Glacial acetic acid dissolved small amounts of pigment when cold, and much larger amounts when hot. A small proportion of the pigment was extracted by prolonged standing with cold water. The aqueous extract of the pigment was not dialysable against distilled water. The pigment could be precipitated by acidifying to $\mathrm{pH} 4.7$ and heating.

All these properties suggested that the substance occurred in the tissues in close association with protein. Protein hydrolysis by acidic, alkaline or enzymic digestion appeared therefore to be the first step necessary for its separation. Hydrolysis with mineral acids was open to the objection that large amounts of melanins were formed, which might in further manipulation have been confused with the original pigment. Hydrolysis with $10 \% \mathrm{KOH}$ produced no melanins, but reduced the intensity of fluorescence. With $\mathrm{Ba}(\mathrm{OH})_{2}$ the loss of fluorescence appeared to be less pronounced, and this reagent, and later proteolytic enzymes, were used in attempts to separate the pigment. In each case the pigmented material eventually obtained had the property of being readily soluble in dilute aqueous alkali, and could be extracted after acidification by shaking it with isobutanol.

Separation by digestion with $\mathrm{Ba}(\mathrm{OH})_{2}$

The uteri of rats which had been kept on a diet deficient in vitamin $\mathrm{E}$ for about a year were freed from visible fat, washed, and digested on a boiling water-bath for about $\mathrm{I} 7 \mathrm{hr}$. with ten times their weight of $3 \% \mathrm{Ba}(\mathrm{OH})_{2}$. The digest was cooled, 
acidified with $\mathrm{HCl}$ to below $\mathrm{pH}_{3}$, and washed several times with light petroleum to remove lipids. The brown pigment was then extracted with several portions of isobutanol, and the combined extracts were washed with $5 \% \mathrm{NaCl}$. The pigment was then transferred back to aqueous solution by several extractions with $0.5 \mathrm{~N}-\mathrm{NaOH}$, and the combined extracts were freed from isobutanol by extraction with ether. Dilute $\mathrm{HCl}$ was then added until precipitation was complete. The precipitate was washed thoroughly with water acidified with $\mathrm{HCl}$, and finally with pure water, and was dried over $\mathrm{P}_{2} \mathrm{O}_{3}$ in vacuo. The dried product was pulverized and repeatedly extracted with ether, and again dried. The product was a light brown powder which showed a yellowish brown fluorescence when irradiated in solution in $\mathrm{NaOH}$ or isobutanol. Normal uterus tissue when submitted to the same treatment gave no appreciable yield of pigment.

\section{Separation by enzymic digestion}

The pigmented uteri, freed from visible fat, were minced and incubated with pepsin at $\mathrm{pH} 2$ for about a week. The non-digested portion was washed, first with water and then with ether, and was next submitted to tryptic digestion for 2 days in $3 \% \mathrm{NaHCO}_{3}$ with the $\mathrm{pH}$ adjusted to about 8 . The digest was acidified, centrifuged, and the precipitate was extracted several times with $\mathrm{I} \% \mathrm{NaHCO}_{3}$. From the combined extracts the pigment was again precipitated by acidification, and was washed with acidified water. The product as prepared by enzymic digestion differed from that obtained by digestion with $\mathrm{Ba}(\mathrm{OH})_{2}$ in being only partially extracted from acid solution by isobutanol. It became completely soluble in isobutanol after being redissolved in $\mathrm{NaHCO}_{3}$ and treated with $\mathrm{Ba}(\mathrm{OH})_{2}$.

Altogether fifteen uteri were extracted by digestion with either $\mathrm{Ba}(\mathrm{OH})_{2}$ or enzymes. The combined yield of pigment amounted to about $20 \mathrm{mg}$.

\section{Properties of the pigment}

The crude pigment could be made lighter in colour without loss of fluorescence by dissolving it in $0.05 \mathrm{~N}-\mathrm{NaOH}$ and treating it with a few drops of $30 \% \mathrm{H}_{2} \mathrm{O}_{2}$. The final product, after this treatment, was soluble in isobutanol, $n$-butanol, and amyl alcohol. It was very slightly soluble in $96 \%$ ethanol and acetone, but insoluble in ether, chloroform, benzene or light petroleum. After solution in dilute alkalis its precipitation on acidification commenced at $\mathrm{pH} 4$. The pigment was non-dialysable against water or dilute alkali. Its absorption spectrum in alcoholic or alkaline solution was continuous in both the visible and ultra-violet regions. It appeared to be resistant to both oxidation and reduction. The pine-splint test for the pyrrole ring was positive, but Gmelin's test for bile pigments was negative. Insoluble salts of the pigment could readily be formed by dissolving it in dilute $\mathrm{NaOH}$, adjusting the $\mathrm{pH}$ to $5^{-6} \cdot 5$, and then carefully adding barium acetate, cupric chloride or ferric chloride.

\section{Results of elementary analysis}

The amount of pigment obtained from uterine tissue was inadequate for analysis, but larger quantities of similar material were prepared from skeletal muscles of deficient rats. The elementary analyses were made by Dr G. Weiler of Oxford, who 
obtained the percentage composition $\mathrm{C} 60 \cdot \mathrm{I}, \mathrm{H} 7 \cdot 67, \mathrm{~N}_{5} \cdot 62$, $\mathrm{S}_{1} \cdot 7$, residue $2 \cdot \mathrm{I}$ including $\mathrm{Fe} 0^{\circ}$, and $\mathrm{O} 22 \cdot 8$. Another preparation from the same source contained $\mathrm{C}_{5} 8 \cdot 8, \mathrm{H}_{7} \cdot 65, \mathrm{~N}_{5} \cdot 09, \mathrm{~S}_{1} \cdot 47$, residue 0.98 and $\mathrm{O}_{26}$.0r.

\section{Preparation of artificial fluorescent substances}

The chemical properties and elementary analysis of the pigment found in vitamin $\mathrm{E}$ deficiency suggested that it might be a protein breakdown product. It was, therefore, of interest to examine the fluorescence of substances of a melanoid* character obtained by the oxidation of proteins and amino-acids.

\section{Oxidation of tyrosine derivatives in aqueous solution}

Although tyrosine derivatives are generally considered to be the most important substrates in the natural formation of melanin, our attempts to use them to produce a stable brown fluorescent pigment met with little success. Melanins formed by treatment of $l$-tyrosine with tyrosinase (Chodat \& Staub, I907) could be extracted with isobutanol, but showed no fluorescence under ultra-violet irradiation.

Adrenaline when treated with tyrosinase gave a product which had intense goldenyellow fluorescence but, on standing, the colour became dark brown and the fluorescence was lost. Treatment also of tyrosine and phenylalanine with $\mathrm{H}_{2} \mathrm{O}_{2}$ and $\mathrm{FeCl}_{3}$ gave rise to dark brown products, which were, however, only slightly soluble in isobutanol and only faintly fluorescent. A solution of di-oxyphenylalanine after being allowed to stand for several days formed by autoxidation a substance which had intense yellow fluorescence, but which was only slightly soluble in isobutanol.

\section{Oxidation of hydrolysed protein in acetic acid}

Discoloured uteri, which had been boiled for a few minutes with a small volume of dilute $\mathrm{H}_{2} \mathrm{SO}_{4}$ (sp.gr. $\mathrm{x} \cdot 2$ ) followed by glacial acetic acid, yielded clear brown solutions which gave a yellow fluorescence under irradiation. When the same treatment was applied to normal uteri or any other muscular tissues, the solution slowly became faintly pink. On addition of an oxidizing agent, such as benzoyl-peroxide, the pink was first intensified to a bright magenta, and then changed to brown. Colour formation by the digest of normal uteri, on the other hand, could be prevented by the presence of a reducing agent, such as ascorbic acid in a concentration of $0.00 \mathrm{r} \%$. The brownness of the colour due to abnormal pigment was not influenced by the presence of ascorbic acid, but careful quantitative experiments with a Zeiss step photometer indicated that the abnormal tissues, in the absence of a reducing agent, produced an underlying pink colour in the same way as normal tissues.

Under irradiation, the final brown solution of the oxidized digest of normal tissues showed some degree of fluorescence which was, however, less yellow and less intense than with abnormal tissues. After dilution of the glacial acetic acid with water the brown colour could not readily be extracted into isobutanol.

* The term 'melanin' is taken to imply a black non-fluorescent pigment, such as that produced in the final stage of the action of tyrosinase on tyrosine. We have used the term 'melanoid' to include all coloured substances produced by the oxidation of proteins or amino-acids, including red intermediate substances and brown substances, but not porphyrins. 


\section{Oxidation of tryptophan and of $\beta$-indolylacetic acid}

When the reactions described above were applied to tryptophan it was found that no colour was produced unless a few drops of concentrated $\mathrm{H}_{2} \mathrm{SO}_{4}$, dissolved in the acetic acid, were substituted for dilute $\mathrm{H}_{2} \mathrm{SO}_{4}$. With this alteration the colour produced by tryptophan was, as expected, much more intense than that given by normal uteri when oxidation was not prevented, and under irradiation a brilliant yellow fluorescence was observed. The final brown colour and fluorescence could not, however, be readily transferred to isobutanol.

Hamence (1943) has already shown that $\beta$-indolylacetic acid, which is of interest both as an animal metabolite and as the plant stimulant hetero-auxin, produces an intense yellowish green fluorescence when heated with conc. $\mathrm{H}_{2} \mathrm{SO}_{4}$. When the procedure with glacial acetic acid and benzoyl-peroxide was applied to this substance an intense magenta colour was developed, even when dilute $\mathrm{H}_{2} \mathrm{SQ}_{4}$ was used. On more prolonged heating the colour changed to brown, and under irradiation an intense yellow-brown fluorescence was observed. In contrast with the experience with tryptophan the brown colour and fluorescence were readily extracted from the diluted solution with isobutanol. The artificial pigment further resembled the natural product in being extracted from isobutanol by dilute alkali, and in being precipitated as a brown scum on acidification after removal of the isobutanol. The precipitate, after being redissolved in isobutanol, showed an intense golden-yellow fluorescence under irradiation.

\section{Other substances}

No colour change or yellow fluorescence was observed when the acetic acid and benzoyl-peroxide treatment was applied to glycine, L-cystine, phenylalanine, tyrosine, histidine, valine, L-leucine, lysine, arginine, glutamic acid, creatinine, asparagine, adrenaline or thyroxine. Haemin dissolved in acetic acid gave a reddish brown colour, which was not intensified by addition of $\mathrm{H}_{2} \mathrm{SO}_{4}$; benzoyl-peroxide made the colour less red, and the solution on irradiation gave a dull yellow fluorescence. Bilirubin gave its characteristic display of bright colours, turning orange, green, blue, violet, red and finally brown, at which stage it displayed intense yellow fluorescence on irradiation. $d l-\alpha$-Tocopherol, which had itself a strong violet fluorescence when irradiated in acetic acid solution, developed on treatment with benzoyl-peroxide a brown colour and yellow fluorescence, both of which could be extracted with ether.

\section{DISCUSSION}

Before discussing the significance of the pigmentation which occurs in the rat deprived of vitamin $\mathrm{E}$, it may be helpful to recall certain similar forms of brown discoloration which have been observed in human subjects or experimental animals.

\section{Pigmentation in the human subject}

In the condition known as haemochromatosis, or bronzed diabetes, brown pigment granules of 'haemofuscin' or 'lipofuscin', which do not stain for iron, are found in the 
smooth musculature of the stomach and intestines. The disease is characterized by the breaking down of haemoglobin. 'Haemosiderin', a pigment rich in iron, is deposited in other sites (von Recklinghausen, I889).

Brown pigment which does not stain for iron has been found also in the heart (Opie, I899) and intestinal musculature (Blaschko, I883; Goebel, 1894) of aged human subjects. Goebel's description of the microscopical appearance of the pigment granules in the muscle cells would serve equally well for that seen in rats after prolonged deficiency of vitamin E. Recently Pappenheimer \& Victor (1946) have found pigment in the livers and other organs of subjects dying from diseases involving chronic intestinal disorders.

\section{Pigmentation in animals}

Nutritional cirrhosis in the rat was found to be often accompanied by the deposition in the liver of a yellow, fluorescent pigment known as 'ceroid' (Lillie, Daft \& Sebrell, 194I). A similar pigment was found in the livers of rabbits poisoned with copper (Mallory, Parker \& Nye, I92I). An appearance known as 'maple-sugar colour' was observed in the intestines of dogs fed with large amounts of liver (Whipple \& RobscheitRobbins, 1925). A diet deficient in vitamin E, and containing $20 \%$ of cod-liver oil, caused the deposition of pigment granules in the adipose tissues of rats (Dam \& Mason, I945); it is not clear whether or not this pigment was the same as that causing 'brown uterus'.

\section{Nutritional factors affecting pigment formation}

Victor \& Pappenheimer (1945) reported that ceroid formation in rats was favoured by protein deficiency, or by the presence in the diet of cod-liver oil or added L-cystine, and was prevented by $\alpha$-tocopherol or choline. An intricate interrelation of nutrients is therefore involved, in which both lipotrophic factors and factors controlling the oxidation of fat appear to play important roles. An interesting point is that cod-liver oil promotes the pigmentation of both ceroid and adipose tissue, which, like discoloration of the uterus, is prevented by administration of $\alpha$-tocopherol.

\section{Possible modes of derivation of the brown pigment}

In view of the increased destruction of erythrocytes in haemochromatosis, von Recklinghausen (1889) assumed that both haemosiderin and haemofuscin were derived from haemoglobin. Opie (1899), however, thought that haemofuscin arose in haemochromatosis from a process in smooth muscle cells similar to that which commonly occurs in old age. Rosenfeld ( $190 \mathrm{O}$ ) also inclined towards this view, particularly since a preparation of the pigment contained more sulphur than would have been expected for a haemoglobin derivative. Sheldon (1934) similarly concluded that haemofuscin as formed in haemochromatosis is probably a melanin, formed by an exaggeration of the normal ageing processes of the muscle cells. It may be noted that our pigment could be separated from the uterus of the vitamin E-deficient rat by an enzymic procedure similar to that employed by Rosenfeld. Since, moreover, the products 
obtained from the human subject and deficient rat had much the same chemical properties and solubilities, it seems safe to assume that they are at least closely related to one another.

Ceroid pigment, as already stated, resembles the pigment of the deficient rat's uterus in so far as its formation may in some circumstances be prevented by administration of tocopherol. These two pigments, however, appear to differ in their distribution in the tissues, and in the shade of their fluorescence. Ceroid, moreover, appears to be different from haemofuscin. Thus, Endicott \& Lillie (I944) 'examined specimens from human cases of haemochromatosis, and found that haemofuscin differed greatly from ceroid in its appearance and staining properties. In their opinion ceroid is a lipid conjugated with the remnants of liver cells. Endicott (1944) detected ceroid in the sites of injection of cod-liver oil or linseed oil into rats, and obtained also artificial preparations with the staining properties of ceroid by incubating cod-liver oil which had been emulsified with gelatin or agar.

The majority of recent workers, therefore, incline to the view that haemofuscin is derived from the protein of muscles, and not from haemoglobin. The brown colour of ceroid, on the other hand, is apparently ascribed primarily to oxidized fat, and not to the attached protein residue. The possibility that bilirubin is involved in the formation of brown pigmentation might be suggested by our observation that this substance gives a brown colour and yellow fluorescence after oxidation. Bile pigments, however, have not been seriously considered by previous workers as sources of either haemofuscin or ceroid pigment. In the vitamin E-deficient rat we have no evidence of jaundice, and it seems most unlikely, therefore, that bilirubin can reach the uterus in amounts sufficient to serve as the precursor of brown pigment.

\section{Chemical nature of the pigment in vitamin $E$ deficiency}

The brown pigment, isolated from rat tissues by the methods we have described, was acidic in behaviour. It differed decidedly from the artificial brown pigment, prepared from tryptophan by oxidation with benzoyl-peroxide, in being extracted by isobutanol from acid aqueous solution. This property suggested that the natural pigment contained less amino-groups than the tryptophan products, since it is presumably the balance between basic and acidic groups which determines the distribution between the aqueous and isobutanol phases. In agreement with this hypothesis the oxidation products of $\beta$-indolylacetic acid were readily extracted by $i$ sobutanol from acidified aqueous solution. The elementary analysis of the pigment, moreover, indicated that the nitrogen content was only $5-5.6 \%$, which is about one-third of the value which would be expected for typical protein. On the other hand, the sulphur content of $1 \cdot 5-1 \cdot 7 \%$ was within the ordinary range for protein. The presence of $\mathbf{I}-2 \%$ of residue indicated that our preparations were still far from pure.

The most plausible explanation of these observations is that in the absence of vitamin $\mathrm{E}$ the muscle proteins tended to become oxidized and partially deaminated to form pigments of the melanoid type. These substances probably fluoresced because of the presence in their molecule of oxidized and de-aminated derivatives of tryptophan. The formation of such products might well be associated with the greatly increased 
oxygen consumption of the dystrophic muscular tissues in a state of vitamin Edeficiency (Houchin \& Mattill, 1942a,b).

An analytical result low in nitrogen could, however, also arise from a combination of a protein residue with oxidized fatty acid, as suggested by Endicott \& Lillie (1944) in connexion with ceroid. Since our pigment, as separated from the muscles of deficient rats, was an amorphous non-greasy solid, it seems on the whole unlikely that substantial amounts of fatty acids entered into its composition. It is quite probable, however, that fat may have been closely involved in the metabolic processes by which it was formed. The role of vitamin $E$ in preventing uncontrolled oxidation in fats would in that case explain the ability of this factor to prevent both our form of pigmentation and ceroid formation.

\section{Vitamin $E$ and protein requirement}

It would appear from the foregoing considerations that vitamin $\mathrm{E}$, among its other functions, prevents the abnormal oxidation of protein. According to this theory we might expect that the presence or absence of vitamin $\mathrm{E}$ would be an important factor in determining the ability of the animal to survive on diets containing inadequate amounts of protein. On this question Dam (1944) has already reported that rats fed upon a diet deficient in protein, but adequate in vitamin $\mathrm{E}$, survived for much longer than rats which were deficient in both protein and vitamin E. Victor \& Pappenheimer (1945) found independently that rats kept on a diet low in protein and deficient in vitamin $\mathrm{E}$ began to lose weight rapidly after the first 4 months, whereas if vitamin $\mathrm{E}$ was given there was no check in growth. Moore (1940) found that vitamin E slightly improved the growth rate of rats on a diet low in protein, but the vitamin caused a similar difference between groups given a normal allowance of protein.

\section{SUMMARY}

I. The brown pigment previously observed in the uterus, skeletal musculature, and other tissues of rats made deficient in vitamin $E$ was found to exhibit a strong yellow or yellow-brówn fluorescence when exposed to ultra-violet irradiation.

2. The fluorescence of the uterus, ovaries and ovarian ligaments could be plainly seen in the early stages of deficiency, before brown pigmentation could be discerned by visible light. In advanced deficiency, fluorescence was widespread, but certain sites, including the urinary bladder and generally the intestines, remained unaffected. Foetuses carried in a pigmented uterus did not show abnormal fluorescence.

3. Little or no brown pigmentation or yellow fluorescence was detected in the tissues of guinea-pigs which had been restricted, when almost fully grown, to a diet deficient in vitamin $E$.

4. The significance of fluorescence observed in human hearts was doubtful in view of the influence of post-mortem changes on the fluorescence of this organ.

5. A brown, fluorescent, pigmented material was separated from affected rat tissues as an amorphous powder. The procedure consisted essentially of digesting the tissues with baryta or enzymes, acidifying and extracting with isobutanol. 
6. The pigment was soluble in dilute alkalis, from which it was precipitated by acidification. It was insoluble in most fat solvents, but dissolved readily in butyl and amyl alcohols and, to some extent, in glacial acetic acid.

7. The elementary analysis indicated a nitrogen content much lower than that of a typical protein. The sulphur content was within the ordinary range for protein.

8. Brown pigments, which showed some degree of fluorescence under irradiation, were obtained by the oxidation of protein digests, usually in solution in glacial acetic acid.

9. Brown oxidation products showing strong yellow fluorescence were obtained from tryptophan by the same procedure, but they differed in their solubility properties from the pigment separated from affected rat tissues. By the oxidation of $\beta$-indolylacetic acid, however, products were obtained which had the same solubility properties as the natural pigment.

Io. The brown fluorescent pigment probably arises in vivo from the abnormal oxidation of protein, and the presence of oxidized and de-aminated groups derived from tryptophan is to be suspected.

II. The pigment, as separated from deficient rat tissues, possessed many of the chemical characteristics described for 'haemofuscin', as separated from human intestines. Its properties, however, differed somewhat from those reported for ceroid, the brown fluorescent pigment which occurs in rats suffering from experimental cirrhosis of the liver.

Our thanks are due to Dr Lucy Wills, of the Royal Free Hospital, and also to Dr F. Bicknell and Captain J. M. Brown, for specimens of human tissues, to Dr L. J. Harris for his valuable criticism, and to Miss A. C. Cooper for technical assistance.

\section{REFERENCES}

Barrie, M. M. O. (1938). Biochem. F. 32, 2 I34.

Barrie Sweeten, M. M. O. (1943). Biochem. F. 37, 523 .

Blaschko, A. (1883). Virchows Arch. 94, I36.

Chodat, R. \& Staub, M. (1907). Arch. Sci. phys. nat. 23, 265.

Dam, H. (1944). Proc. Soc. exp. Biol., N.Y., 55, 55.

Dam, H. \& Mason, K. E. (1945). Fed. Proc. 4, I 53.

Demole, V. (194I). Schweiz. med. Wschr. 71, 125I.

Endicott, K. M. (1944). Arch. Path. Lab. Med. 37, 49.

Endicott, K. M. \& Lillie, R. D. (1944). Amer. F. Path. 20, 149.

Evans, H. M. \& Emerson, G. A. (1943). F. Nutrit. 26, 555.

Faria, J. L. de (1946). O Hospital, Rio de Faneiro, 29, 583.

Goebel, C. (1894). Virchows Arch. 136, 482.

Hamence, J. H. (1943). Analyst, 68, 636.

Hessler, W. (194I). Z. Vitaminforsch. II, 9.

Houchin, O. B. \& Mattill, H. A. (1942a). F. biol. Chem. 146, 301.

Houchin, O. B. \& Mattill, H. A. (1942 b). F. biol. Chem. 146, 309.

Lillie, R. D., Daft, F. S. \& Sebrell, W. H. (1941). Publ. Hlth Rep., Wash., 56, 1255.

Mallory, F. B., Parker, F. \& Nye, R. N. (192 I). F. med. Res. 42, 46r.

Martin, A. J. P. \& Moore, T. (1936). Chem. E Ind. 55, 236.

Martin, A. J. P. \& Moore, T. (1938). Chem. E Ind. 57, 973.

Martin, A. J. P. \& Moore, T. (1939). F. Hyg., Camb., 39, 643.

Mason, K. E. \& Emmel, A. F. (1945). Anat. Rec. 92, 33.

Moore, T. (1940). Biochem. F. 34, I 32 I. 
Moore, T. \& Wang, Y. L. (1943). Biochem. F. 37, i.

Oliveira, D. de (1946). O Hospital, Rio de Faneiro, 29, 573.

Opie, E. L. (1899). F. exp. Med. 4, 279.

Pappenheimer, A. M. \& Schogoleff, C. (1944). Amer. F. Path. $20,239$.

Pappenheimer, A. M. \& Victor, J. (1946). Amer. F. Path. 22, 395.

Recklinghausen, F. D. von (1889). Tageblatt der 62. Versammlung deutscher Naturforscher und Aerzte, Heidelberg, p. 324 .

Ringsted, A. (1935). Biochem. F. 29, 788.

Rosenfeld, M. (1901). Arch. exp. Path. Pharmak. 45, 46.

Sheldon, J. H. (1934). Lancet, 227, 1031.

Victor, J. \& Pappenheimer, A. M. (1945). F. exp. Med. 82, 375.

Whipple, G. H. \& Robscheit-Robbins, F. S. (1925). Amer. $\mathscr{F}$. Physiol. 72, 395.

\title{
A Study of the Composition of Sow's Milk
}

\author{
BY R. BRAUDE, M. E. COATES, K. M. HENRY, S. K. KON, \\ S. J. ROWLAND, S. Y. THOMPSON AND D. M. WALKER \\ National Institute for Research in Dairying, University of Reading
}

(Received 25 April 1947)

Most of the scanty literature on the major constituents of sow's milk is old, and nothing has to our knowledge been published on its vitamin composition, with the exception of the fragmentary information about vitamins $\mathrm{A}$ and $\mathrm{C}$ mentioned below. Probably the main reason for this relative lack of information is the difficulty of obtaining satisfactory samples of sow's milk. This difficulty is stressed in every paper published on the subject, and is connected with the mechanism of the 'let down' of milk over which the sow appears to have complete control. It is well known that milk cannot be obtained from the sow by milking in the way normally effective with other large animals. Small samples of milk have been obtained mainly by subterfuge. For this purpose a piglet had to be quietly removed while the sow was suckling her litter and the vacated teat quickly milked by hand. Elly \& Petersen (194I) have lately devised a method for inducing the 'let down' of milk in the cow by the injection into her blood stream of the oxytocic principle of the pituitary. We have applied their technique to the sow with very satisfactory results, and have been able to obtain with ease from a number of sows large samples of milk at intervals throughout lactation. These samples have been analysed for major constituents and also for certain vitamins. We also obtained colostrum from the same sows in a way previously described (Braude, Kon \& Thompson, I945-6) for comparison of its composition with that of the milk. The investigation has covered the winter as well as the summer feeding of the sow, and has included a study of the effect of season and fodder on the composition of colostrum and milk. Biological tests with guinea-pigs were also done to confirm the extraordinary richness of sow's colostrum in ascorbic acid reported in our earlier paper (Braude et al. 1945-6). 